\title{
The Research on Dynamical Alliance Formation and Partner Selection of Third Party Logistics Enterprises
}

\author{
Jin Chen ${ }^{1, a}$ and Haiqing $\mathrm{Bai}^{2}{ }^{2}{ }^{*}$ \\ ${ }^{1}$ Department of Commerce, Xiamen City University, Xiamen, 361008, China \\ ${ }^{2}$ School of Journalism and Communication, Xiamen University, Xiamen, China \\ a181357314@qq.com, bHaiqing.bai@xmu.edu.cn \\ *The corresponding author
}

Keywords: Small and medium sized third party logistics enterprises; Dynamic alliance; Analytic hierarchy process; Partner selection

\begin{abstract}
Aiming at the problems of weak competitive ability and low level service of small and medium sized third party logistics enterprises in our country, from the perspective of dynamic alliance, this article studies alliance formation and partner selection of third party logistics enterprises. Taking qualitative and quantitative indicators into account, partner selection model based on fuzzy analytic hierarchy process is put forward. Case study illustrates the practicability of this model and help logistics enterprises find suitable alliance partners to improve the competitiveness and service level of enterprises.
\end{abstract}

\section{Introduction}

Most of third party logistics enterprises in China are small and medium sized logistics enterprises, in aspects such as capital, scale, network and services level, there is a big gap between them and foreign logistics enterprises, as well as domestic integrated logistics companies, so they are inferior in competition. Small and medium sized logistics enterprises will face two choices, being purchased or merged in competition; Orstarting with sourcing, funding and network formalization, they integrate internal and external resources, and take the road of large-scale management. Therefore, Chinese small and medium sized logistics enterprises start to think about their development direction. Dynamic alliance becomes the focus of attention and discussion for small and medium logistics enterprises. Under current logistics system in China, due to the serious profession division of logistics industry, many logistics companies belong to different departments, so the obstacle of cross-industry and cross-region merger system is obvious. Therefore, cooperation among enterprises based on dynamic alliance becomes an effective solution [1], especially flexible, non-equity loose dynamic alliance without property merger is most representative. The dynamic alliance construction of third party logistics enterprises is one of valid forms. Participating in market competition in the form of dynamic alliance based on logistics business, is the inevitable choice for their survival and development.

Partner selection in dynamic alliance is directly related to the dynamic stability of whole dynamic alliance, whether dynamic alliance can succeed in operation and meeting customers' need sto establish customer loyalty and bring more benefits for company. But partner selection in dynamic alliance of Chinese third party logistics enterprises always has following defects: simple selection process, defective evaluation system and great subjective capriciousness. So the study of partner selection in dynamic alliance for third party logistics enterprises, and establishing a complete, scientific selection system and simple practical choice selection methods are necessary.

\section{The Connotation of Third Party Logistics Enterprises' Dynamic Alliance}

Third party logistics enterprises' dynamic allianceis a logistics organization which sprang up in late 1990s.It is a temporary alliance formed by several logistics companies with different key resources in order to respond rapidly to a market opportunity [2]. It is initiated by a core logistics enterprise 
with core competence, and united with several logistics companies of professional and complementary characteristics, through logistics activity alliance formed by information technology and information network to complete logistics tasks. Logistics enterprises form logistics partnership of mutual trust, risk shared and benefits shared, while the independence of logistics members enables each member can focus on work of own expertise, and it forms an organizational situation of powerful combination. In terms of logistics services, complementary advantage can create competitive advantage and maximize the benefits of the whole alliance. This alliance is produced because of opportunity, and it also comes to an end with the completion of tasks. When the next opportunity comes, there starts a new round of forming alliance.

\section{The Purpose of Chinese Small and Medium Third Party Logistics Enterprises Forming Dynamic Alliance}

Cultivate and Enhance the Core Competitiveness of Enterprises. In terms of constructing and cultivating core competitiveness, Chinese small and medium sized third party logistics enterprises can draw upon the development experience of international logistics giants, like scientific analysis and accurate market strategic positioning, focusing on core business, improvement and innovation, seeking differentiation, scientific management [3] and so on.

Expand Logistics Service Scale, Reduce Logistics Service Cost. Economies of scale is an important part of production organization theory, and it reveals the relationship between production scale and economic effects, quantity fluctuation of products or services and unit cost of products or services. Logistics business requires specialized logistics equipment, efficient system, and high level fixed capital investment, so the fixed cost takes a large proportion of total cost. Scale expansion can let average logistics cost show a downward trend.

Improve the Level and Quality of Logistics Service. According to time, cost and efficiency of logistics, compared with logistics demand, the accuracy and transport timeliness rate of Chinese logistics service level are relatively low, $4 \%$ and $8 \%$, respectively. But damage rate is as high as $2.2 \%$, so it is hard to balance between supply and demand [4]. To Chinese small and medium sized third party logistics enterprises, they need to cooperate with related logistics enterprise through appropriate methods. Under the principle of "mutual benefit and reciprocity, resources sharing", they should optimize logistics resource allocation of the whole alliance, develop logistics information platform together to form national or regional logistics service network or business alliance, and provide customer specialization and integration logistics services to improve logistics service level.

\section{Dynamic Alliance Construction and Partner Selection of Third Party Logistics Enterprises}

Dynamic Alliance Construction of Third Party Logistics Enterprises. Dynamic alliance of third party logistics enterprises is a new organizational form for third party logistics enterprises to adapt to market competition environment. Its formation is a complex project, involving a wide range of conditions and factors. In general, dynamic alliance enterprises combine due to the appearance of market opportunities, and alliance disintegrates because of the disappearance of market opportunities, so the dynamic alliance enterprises' life periodicity is extremely obvious. (Strader (1998) [4], Kanet (1999) [5], Li (2001) [6], Bernhard (2001) [7]) Throughout the whole life periodicity of dynamic alliance, there are four stages of preparation, formation, operation and disintegration. As shown in Fig. 3-1.

Preparation period: Logistics alliance identifies and analyzes the logistics demand information at its disposal, and ultimately determines whether to form logistics enterprises dynamic alliance to seize opportunities in logistics market. Logistics alliance's main tasks are: market opportunity identification, core competency identification and operation mode selection.

Formation period: management content of formation period includes partner selection, organization mode selection, agility metrics of dynamic alliance enterprises, resources reorganization and dynamic enterprise information system construction. 
Operational period: management content of operation period includes interest distribution mechanism development, trust management, task distribution and coordination, operation supervision. At this point, third party logistics enterprise dynamic alliance begin to provide logistics services for customers, including logistics process cohesion, quality management of logistics services, logistics cost control. Dynamic alliance's operation requires harmonization among all logistics partners, through feedback and coordination mechanism, logistics enterprise dynamic alliance continues to make appropriate adjustment to the last phase of operation mode.

Disintegration period: When market opportunities are basically seized, dynamic alliance is disintegrated. Management content of disintegration period includes project termination identification, benefits distribution, transaction processing after disintegration and comprehensive performance assessment.

Dynamic Alliance Partner Selection of Third Party Logistics Enterprises. Principles of Partner Selection. Facing an opportunity of market demand, core enterprise needs to outsource part of its logistics business or logistics to establish short or long term logistics alliance. Core enterprise first acquires a core competency (which can be business, organization, design competency and so on), to acquire a core position, then the business process of the entire logistics chain can be settled, and it needs to select partners with same core competency for outsourcing business processes.

In partner selection process, depending on enterprise dynamic alliance's formation and specific tasks, different selection principles and standards are established, but there are still a few basic principles as follows:(1) Principle of core competence. One of the purposes of setting up dynamic alliance enterprises is to obtain complementary advantages, and this advantage is the core competence of members [8].(2)Principles of cost-effective. This principle not only refers to the total actual operating costs of enterprise dynamic alliance (including connection costs) should not exceed the individual internal costs of all completion, but also means through the cooperation of members, allied parties can eventually get $1+1>2$ synergic effect.(3)Principles of agility. This principle requires that the service requests from outside of dynamic alliance or among alliance partners have quick reaction feature. (4) Principle of mutual trust. Establishing full trust relationship and eliminating the hidden danger of trust crisis, is one of the principles and standards for selecting partners and also the premise to improve the operating efficiency of network organization. (5) Principle of risk minimization. In selecting partners, risks must be carefully considered, and choose the right partners to avoid or reduce the risk of dynamic alliance enterprise operation to the greatest extent.

Due to different specific problems and the differences in specific objectives, when dynamic alliance enterprises select partners, they won't restricted in the above principles, for example some dynamic alliance enterprises focusing on expanding market will also consider the geography of partners, their reputation and brands and so on.

Partner Selection Model Based on AHP. (1)Defects of traditional methods

There are many methods to select partners, and they are generally determined according to the number of logistics partners, the understanding of logistics partners' abilities and demand for logistics projects [9]. There are two main categories. First is qualitative analytical selection method. It is mainly based on past experience and previous relationship to select partners. Second is quantitative selection method. The following are some of the commonly used ways: First is intuitive judgment method, based on consultation, survey data and people's judgment to analyze and assess partners. This method is simple and commonly used to select non-leading logistics partners. Second is bidding method, it can be public tender or designated emergency tender. This method is competitive, and enterprises can select appropriate partners in a broader range to obtain favorable, cheap and applicable materials. But the procedure is complicated and takes long time, so it is easy to lose the chance of logistics projects competition. Third is consultation method, due to the full consultation of both supply and demand sides, price, service and coordination are assured.

Because index system of third party logistics enterprises partners based on dynamic alliance usually involves a number of qualitative and quantitative indicators, but above methods focus either 
on qualitative indicators like information system indicator, corporate culture indicator and knowledge indicators, or on quantitative indicators such as price indicator, so they cannot select partners accurately [10].

(2) Fuzzy AHP analytic hierarchy process

Due to the shortcomings and drawbacks of above methods, this article uses analytic hierarchy process (AHP) model to do analysis, based on index system features of dynamic alliance third party logistics partners.

AHP method is a multi-objective and multi-criteria decision analysis method proposed by renowned operational experts T. L. Saaty, Weber in the 1970s. As a multi-objective decision analysis method combining with qualitative and quantitative approaches, AHP has high reliability and minor error, and is widely used in many fields currently [11, 12]. AHP is a good solution to solve the imbalance problem in traditional methods, and it is a method combining qualitative and quantitative approaches together. Especially, it quantifies decision maker's experience and judgments and it can be more practical under the condition of complex structure of target (factor) and lack of necessary data. This article uses fuzzy AHP to analyze the problems, based on index system features of dynamic alliance third party logistics partners. It can be divided into four steps:(1) Analyze the relationship among elements in system, and establish hierarchical structure of system; (2) Compare the standards importance of each element in same level with previous level, and judge matrix based on comparison;(3) Calculate the relative weight of elements being compared to this criteria according to matrix judgment;(4) Calculate assessment scores of various projects and rank them.

\section{Case Analysis}

This section explains partner selection process of fuzzy AHP third party logistics partner selection model by case studies.

Case Background. Shanghai supply chain management Company A is a supply chain service provider of specialized chemical products. The company constructs supply chain electronic commerce platform (hereinafter referred to as: business platform), and it provides one-stop procurement outsourcing services for world's middle and downstream chemical manufacturers and enterprises demanding chemical products through business platform based on procurement outsourcing, extending to deep supply chain management service, to provide customers with logistics planning and implementation, supply chain financial settlement, import and export proxy, information services, global distribution, joint demand forecasting, production planning, joint inventory management, automatic replenishment and supply chain services.

Based on above characteristics, in logistics operation of daily chemical products, A Company uses dynamic alliance method to build partnership with third party logistics enterprises. Due to the particularity of chemical products, A Company issues project instructions to a number of third-party logistics enterprises and puts forward specific requirements for logistics operation. Suppose there are 4 third party logistics companies participating in bidding. A Company wishes to find its own logistics partners to build dynamic alliance in these 4 third party logistics enterprises. This is a typical case of logistics outsourcing partner selection.

Dynamic Alliance Partner Selection Model of Third Party Logistics Enterprises. Comprehensive Quality Evaluation. company first uses AHP method to make comprehensive quality evaluation of these 4 third-party logistics companies. According to evaluation index system and industry characteristic of third party logistics dynamic alliance partners, it makes logistics (hazardous article) operational qualification, logistics cost, service level and quality, partnership, information availability as basic criteria.

Judgment Matrix Establishment, Single Hierarchical Arrangement and Consistency Judgment. Bringing together experts' advices, A Company establishes evaluation system for third party logistics companies C1, C2, C3, C4 candidates, as shown in Table 4-1, and assesses indicators, gets a matrix as shown in Table 4-2 through formula (4.1), the defuzzifies it through formula (4.2) and 
gets a matrix as shown in Table 4-3.

$$
A_{i j}=\left(c_{i j}, a_{i j}, b_{i j}\right) \text { 且 }\left\{\begin{array}{l}
c_{i j}=\min \left(c_{i j}^{(1)}, \cdots, c_{i j}^{(n)}\right) \\
a_{i j}=\sqrt[n]{\left(\prod_{k=1}^{n} a_{i j}^{(k)}\right)} \\
b_{i j}=\max \left(b_{i j}^{(1)}, \cdots, b_{i j}^{(n)}\right)
\end{array}\right.
$$

Table 1 Fuzzy matrix formed by a number of experts' assessments

\begin{tabular}{|l|c|c|c|c|c|}
\hline $\mathrm{A}$ & $\mathrm{B} 1$ & $\mathrm{~B} 2$ & $\mathrm{~B} 3$ & $\mathrm{~B} 4$ & $\mathrm{~B} 5$ \\
\hline $\mathrm{B} 1$ & $(1,1,1)$ & $(1 / 5,1 / 3,1 / 2)$ & $(4,6,7)$ & $(1,2,4)$ & $(3,5,6)$ \\
\hline $\mathrm{B} 2$ & $(2,3,5)$ & $(1,1,1)$ & $(1,2,2))$ & $(1,1,2)$ & $(1 / 2,1,1)$ \\
\hline B3 & $(1 / 7,1 / 6,1 / 4)$ & $(1 / 2,1 / 2,1)$ & $(1,1,1)$ & $(3,4,6)$ & $(1 / 4,1 / 2,1)$ \\
\hline B4 & $(1 / 4,1 / 2,1)$ & $(1 / 2,1,1)$ & $(1 / 6,1 / 4,1 / 3)$ & $(1,1,1)$ & $(1 / 8,1 / 6,1 / 5)$ \\
\hline B5 & $(1 / 6,1 / 5,1 / 3)$ & $(1,1,2)$ & $(1,2,4)$ & $(5,6,8)$ & $(1,1,1)$ \\
\hline
\end{tabular}

$$
D A_{i j}=\frac{\left(b_{i j}-c_{i j}\right)+\left(a_{i j}-c_{i j}\right)}{3}+c_{i j}=\frac{c_{i j}+a_{i j}+b_{i j}}{3}
$$

Table2 Relative importance weight and priority weight vector of each criterion in criterion level after defuzzification

\begin{tabular}{|c|c|c|c|c|c|c|}
\hline A & B1 & B2 & B3 & B4 & B5 & $W^{(1)}$ \\
\hline B1 & 1 & $1 / 3.33$ & $1 / 5.66$ & $1 / 2.33$ & $1 / 4.66$ & 0.054 \\
\hline B2 & 3.33 & 1 & $1 / 1.66$ & 1.33 & $1 / 1.33$ & 0.180 \\
\hline B3 & 5.66 & 1.66 & 1 & 4.33 & $1 / 2.33$ & 0.275 \\
\hline B4 & 2.33 & $1 / 1.33$ & $1 / 4.33$ & 1 & $1 / 6.33$ & 0.091 \\
\hline B5 & 4.66 & 1.33 & 2.33 & 6.33 & 1 & 0.401 \\
\hline \multicolumn{7}{|c|}{ C.R=0.06 } \\
\hline
\end{tabular}

Through a number of experts' comparative assessment on criterion level and scheme level we get relative important weight of criterion level to scheme level, priority weight vector, as well as consistency coefficient.

Total Order of Levels and Consistency Check. Priority weight vectors of four alternative third party logistics companies in scheme level to various criteria in criterion level $p_{j}^{2}(\mathrm{j}=1,2,3,4,5)$ form $4 * 5$ matrix as :

$$
\begin{aligned}
& \mathrm{P}^{(2)}=\left(p_{1}^{(2)}, p_{2}^{(2)}, p_{3}^{(2)}, p_{4}^{(2)}, p_{5}^{(2)}\right) \\
& =\left[\begin{array}{llllc}
0.165 & 0.338 & 0.577 & 0.103 & 0.11 \\
0.437 & 0.080 & 0.097 & 0.593 & 0.226 \\
0.275 & 0.430 & 0.135 & 0.079 & 0.076 \\
0.123 & 0.152 & 0.192 & 0.225 & 0.588
\end{array}\right]
\end{aligned}
$$

Combined priority weight vector of four third party logistics companies to goal A is:

$$
\mathrm{W}=\left(\left(\omega_{1}, \omega_{2} \omega_{3}\right)^{T}=p^{(2)} \omega^{(C)}\right.
$$




$$
\begin{aligned}
& =\left[\begin{array}{ccccc}
0.165 & 0.338 & 0.577 & 0.103 & 0.11 \\
0.437 & 0.080 & 0.097 & 0.593 & 0.226 \\
0.275 & 0.430 & 0.135 & 0.079 & 0.076 \\
0.123 & 0.152 & 0.192 & 0.225 & 0.588
\end{array}\right]\left[\begin{array}{l}
0.054 \\
0.180 \\
0.275 \\
0.091 \\
0.401
\end{array}\right] \\
& =(0.281,0.209,0.167,0.343)^{\mathrm{T}} \\
& \text { Therefore, } \omega_{1}=0.281, \omega_{2}=0.209, \omega_{3}=0.167, \omega_{4}=0.343
\end{aligned}
$$

The sorting result of four third party logistics companies is: $\alpha_{4} \succ \alpha_{1} \succ \alpha_{2} \succ \alpha_{3}$, the fourth A4 third party logistics company is the best.

Thus it can be seen, AHP index system can accurately reflect the present situation and future development direction of third party logistics enterprises and is representative. By the method of fuzzy mathematics, we can get a number of experts' opinions to have group decision making, and make it as scientific and objective as possible. The method is simple and easy to calculate, which facilitates the operation of corporates' decision makers.

\section{Conclusion}

Competitive situation of logistics industry in China shows that: small and medium sized third party logistics enterprises are with little capital and narrow service area, so it is difficult for them to provide one-stop logistics services independently. Facing strong foreign competitors and domestic logistics expansion, small and medium sized third party logistics enterprises are in a weak position. So for small and medium sized third party logistics enterprises, selecting appropriate logistics enterprises to form dynamic alliance and achieving partner union with own core logistics skills, can change the weak positions of small and medium sized enterprises in competition, improve logistics service level effectively and ensure the sustainable development of enterprises.

Partner selection of logistics enterprises dynamic alliance is the basic problems faced by its members. Based on traditional selection methods, this article presents logistics enterprises partner selection model based on fuzzy AHP. When this model proposing logistics partner selection index, it overcomes the defects of only considering qualitative indicators or quantitative indicators in traditional selection methods, quantifies the method of using AHP to qualitative indicators, and makes the selection results more in line with actual situation. Finally, the case study of a logistics enterprise selecting partner and its actual computed results illustrate the utility of this mode land help logistics enterprises find suitable alliance partners in a better way.

\section{References}

[1] Zhang Qingshan, You Mingzhong. The coordination mechanism of enterprises dynamic

[2] Li Y, Liao X. Decision support for risk analysis on dynamic alliance [J]. Decision Support Systems, 2007, 42(4): 2043-2059.

[3] http://www.chinawuliu.com.cn/oth/content/200701/200721421.html.

[4] Strader T J, Li F R, Michael J. Shaw. Information infrastructure for electronic virtual organization management [J]. Design Support Systems, 1988, (23): 75-94.

[5] Kanet J J, Faisst W, Mertens P. Application of information technology to a virtual enterprise broker: The case of bill Epstein [J]. Production Economics, 1999, (62): 23-32.

[6] Li M H, Fu L C. A virtual factory based approach to On-line simulation and scheduling for an FMS and a case study [J], Journal of Intelligent Manufacturing. 2001, (12): 269-279.

[7] Bernhard K, Marcel D. A toolset for building the virtual enterprise [J]. Journal of Intelligent Manufacturing, 2001, (12): 121-131. 
[8] Prahalad C K, Hamel G. The core competence of the corporation [J], Harvard Business Review, 1990, 68(3): 79-91.

[9] Wang Faming, Liu Dan. The study on partner selection of key enterprises in industrial technology innovativealliance [j]. Research on Science, 2016, 34 (02): 246-252.

[10]Chen Juhong, Wang Yingluo, Sun linyan. Study on virtual enterprise partner selection process and methods [J]. Systematic Engineering Theory and Practice, 2001, 21 (7): 48-53.

[11] $\mathrm{Ng}$ C Y. Evidential reasoning-based fuzzy AHP approach for the evaluation of design alternatives' environmental performances [J]. Applied Soft Computing, 2016, 46: 381-397.

[12]Li C, Anavatti S G, Ray T. Analytical hierarchy process using fuzzy inference technique for real-time route guidance system [J]. IEEE Transactions on Intelligent Transportation Systems, 2014, 15(1): 84-93. 